\title{
Improving Cancer Survivorship Care for Latino Adolescent, Young Adult Survivors Through Community-Partnered Participatory Research
}

\author{
Jacqueline N. Casillas ${ }^{1}$, Patricia A. Ganz ${ }^{2}$, Katherine Kahn ${ }^{3}$, Margaret Stuber ${ }^{4}$, Roshan Bastani ${ }^{5}$, Lindsay F. Schwartz ${ }^{6} \mathbb{0}$, Sonia \\ Morales $^{7}$, Joshua Macadangdang ${ }^{8}$, Emma K. Lidington ${ }^{9}, K$ arla Quintana ${ }^{10}$, Amri Gonzalez $^{10}$, Esther Casas ${ }^{10}$, Elvia Barboa ${ }^{10}$ \\ ${ }^{1}$ Department of Pediatrics, Hematology-Oncology, UCLA David Geffen School of Medicine; Division of Cancer Prevention and Control Research, UCLA Jonsson \\ Comprehensive Cancer Center, ${ }^{2}$ Division of Cancer Prevention and Control Research, UCLA Jonsson Comprehensive Cancer Center; Department of Medicine, \\ Hematology-Oncology, UCLA David Geffen School of Medicine; Department of Health Policy and Management, UCLA Fielding School of Public Health, 3 \\ Department of Medicine, UCLA David Geffen School of Medicine, ${ }^{4}$ Department of Psychiatry, UCLA David Geffen School of Medicine, 5 Department of Health \\ Policy and Management, UCLA Fielding School of Public Health, ${ }^{6}$ Department of Pediatric Hematology-Oncology, University of Chicago, 7 Department of \\ Pediatric Hematology-Oncology, Children's Hospital of Orange County, ${ }^{8}$ UCLA Department of Nursing, ${ }^{9}$ London School of Hygiene and Tropical Medicine, 10 \\ Padres Contra El Cáncer (PADRES) \\ Keywords: community-partnered participatory research, community health research, cancer, adolescent and young adult, Latino/a \\ https://doi.org/10.35844/001c.29534
}

Journal of Participatory Research Methods

Vol. 2, Issue 3, 2021

\section{Background}

Minority adolescent and young adult (AYA) cancer survivors experience disparities in receipt of survivorship care.

\section{Objective}

This study describes the infrastructure of a community-partnered participatory research (CPPR) project between a community-based organization and a National Cancer Institute (NCI)-designated cancer center to develop culturallytailored interventions to improve Latino AYA cancer survivor knowledge regarding their need for survivorship care.

\section{Methods}

Research team participants included the community organization and NCI cancer center directors, research coordinators, a community liaison, and crosstraining program interns. Through use of Jones' theoretical framework, additional stakeholders from academic and community settings were identified and invited to participate in the research team. A process evaluation and qualitative interviews were conducted to assess equal partnership between community and academic stakeholders and determine if the infrastructure followed the five core principles of CPPR. A grounded theory approach was used to analyze qualitative data.

\section{Conclusions}

CPPR between an NCI-designated cancer center and a community-based organization is a new research model for conducting minority AYA cancer survivor outreach. Open communication was critical in engaging the Latino community to discuss their survivorship needs. Community stakeholders were key to infrastructure success through fostering a cohesive partnership with and acting as the voice of the Latino community. Implementing a cross-training program promoted continued engagement of community members with

\footnotetext{
a Corresponding author: Jacqueline N. Casillas, MD, MSHS Department of Pediatrics Division of Hematology-Oncology UCLA David Geffen School of Medicine 10833 Le Conte Avenue, A2-410 MDCC MC 175217 Los Angeles, CA 90095-1752

Telephone: 310-825-5050

Fax: 310-206-8089

Email: jcasillas@mednet.ucla.edu
} 
academic partners. Proper infrastructure development is critical to building successful research partnerships in order to develop culturally-tailored interventions to improve survivorship care knowledge.

\section{Background}

There are more than 700,000 pediatric, adolescent, and young adult (AYA) cancer survivors in the United States (Howlader et al., 2019; Miller et al., 2016). Of these, more than $60 \%$ will suffer from long-term chronic health problems, known as late effects, due to their treatment (Bhakta et al., 2016; Gleeson \& Shalet, 2001; Hallquist Viale, 2016; Hudson \& Patte, 2008; Lewis et al., 2014). These late effects occur from several years to decades after the conclusion of the cancer treatment and carry an increased risk of early death (Gleeson \& Shalet, 2001; Hallquist Viale, 2016; Hudson et al., 2003; Mertens et al., 2001). Although there has been research studying late effects of childhood cancer survivors, there is still a need to further delineate racial and ethnic subpopulation data (Colon-Otero et al., 2008; Im et al., 2008; Nguyen et al., 2014). AYA cancer survivors of racial/ethnic minority groups, especially Latino populations, experience significant health disparities in survivorship care compared to their White peers (Casillas et al., 2011; Munoz et al., 2016; Stolley et al., 2015). Specific barriers to survivorship care in this population include: 1) language and health literacy barriers as well as difficulties accessing cancer information; 2) increased struggles in navigating the fragmented United States health care system compared to other sub-populations of survivors; and 3) cancer stigma lasting sometimes decades after their treatment has finished, making it difficult to discuss and seek out care (Berg et al., 2016; Casillas et al., 2010; Institute of Medicine, 2001; Medlow et al., 2015; Surbone \& Halpern, 2016). Therefore, new research models are needed for outreach to minority AYA cancer communities to develop and evaluate interventions that improve receipt of survivorship care.

Community-partnered participatory research (CPPR), a variant of community-based participatory research (CBPR), is one such model that could be used to develop and evaluate interventions to improve survivorship care, specifically for Latino AYA cancer survivors (Kaur et al., 2012). This model supports collaborative research efforts between researchers and community members to address conditions disproportionately affecting underserved populations, particularly emphasizing equal partnership between research institutions and community organizations throughout the entire design and implementation process of intervention. CPPR development is based on five core principles: 1) openness; 2) redirected power; 3) respect for diversity; 4) equality; and 5) an asset-based approach (L. Jones, Meade, Forge, Moini, et al., 2009). Although CPPR has been effective for conducting research studies in various minority and socially-disadvantaged adult cancer populations, no prior studies have utilized CPPR models for minority AYA cancer survivor populations (B. L. Jones et al., 2010). 
The objective of this study is to describe the infrastructure, defined as the organizational structure and guiding principles, used to create a CPPR collaborative partnership between a National Cancer Institute (NCI)designated cancer center, the University of California Los Angeles (UCLA) (National Cancer Institute, 2019), and a community-based organization, Padres Contra El Cáncer (PADRES). This partnership was established to develop culturally-tailored interventions to improve knowledge of late effects and confer the benefits of receiving survivorship care for Latino AYA cancer survivors. We will describe the development of this partnership, key elements that led to its success, and lessons learned using the five core principles of CPPR.

\section{Methods}

\section{Community-Academic Partnership}

Community Partner: PADRES is a community-based nonprofit institution committed to improving the quality of life for Latino children, adolescents, and young adults diagnosed with cancer up to the age of 21 . PADRES provides culturally-relevant and linguistically-appropriate programs to bridge gaps in access to medical care and knowledge regarding cancer treatment and survivorship (Padres Contra El Cáncer, 2012).

Academic Partner: The Pediatric, Adolescent, and Young Adult Cancer Survivorship Program is embedded within the Division of Cancer Prevention and Control at UCLA's Jonsson Comprehensive Cancer Center, an NCIdesignated cancer center (National Cancer Institute, 2017). The program consists of clinical services, research, and community outreach.

Partnership of the Project: PADRES and UCLA directors had a 10-year relationship prior to the start of the formal partnership described in this manuscript, working on community outreach efforts to improve access to care for the Latino cancer survivor population. Their previous collaborative study, using CBPR methodology, identified barriers and facilitators to accessing survivorship care for Latino AYA survivors (Casillas et al., 2010). However, despite this long-standing relationship, there was no formalized research infrastructure to support community-partnered research across UCLA and PADRES. Therefore, the directors built upon this previous experience to mutually apply for a P20 grant provided by the National Institute of Health (NIH) in Feasibility Studies for Collaborative Interactions for Minority/ Cancer Center Partnership (Feasibility Studies for Collaborative Interactions for Minority/Cancer Center Partnership, 2009). Figure 1 depicts the overall structure and processes used to build the infrastructure described in this manuscript.

UCLA served as the Institutional Review Board (IRB) of record for both PADRES and UCLA. Their IRB committee reviewed and approved this project (UCLA IRB\#10-002246). In-service training on research methods was provided to PADRES staff, as they had not previously conducted independent research. PADRES staff participated in all phases of study design, implementation, data analysis and interpretation, as well as dissemination of 


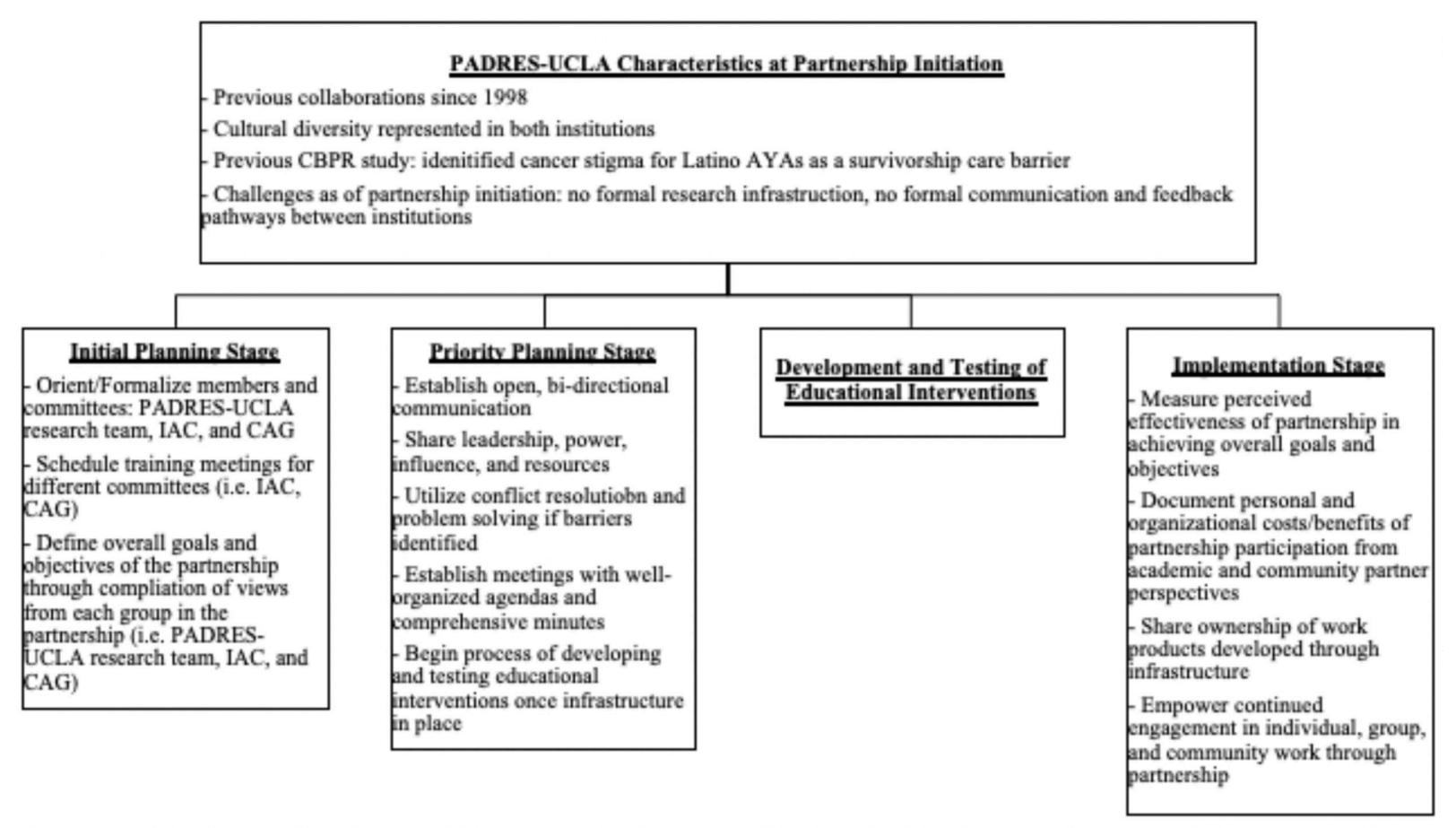

Figure 1. Infrastructure Development Process

project findings. To further develop the research infrastructure within PADRES, a community liaison staff member was hired. The liaison met the following criteria that were mutually agreed upon by the PADRES and UCLA directors: 1) experience working in the Latino cancer community; 2) experience with qualitative and quantitative research methods; 3) previous experience as a health educator or community activist; and 4) bilingual in Spanish and English. The liaison helped facilitate equal participation among community and academic members by observing levels of participation, addressing community concerns, and working alongside the PADRES-UCLA research team. The PADRES and the UCLA directors wrote the job description used for the liaison's recruitment based upon a discussion that determined it would be imperative for an experienced community member to help recruit the Community Advisory Group (CAG) members (see below for further description), lead the CAG meetings, address immediate concerns raised by CAG members, and verify the CAG role was properly represented in the research process. In addition, the PADRES and UCLA directors also mutually agreed that the community liaison should work with the PADRESUCLA research team to help understand the needs and assets of the community. 


\section{Core Partnership Members}

PADRES and UCLA Directors ( $\boldsymbol{n}=2)$ : The directors provided joint leadership throughout all phases of the research project. Both directors participated in the scientific writing of the NCI grant proposal and collaboratively wrote the guidelines for partnership formation. The directors met monthly, alternating between the community and academic sites.

Cross-Training Interns ( $\boldsymbol{n}=\mathbf{4})$ : PADRES had an existing internship program model, which was committed to training underrepresented minority (URM) students in the health career pipeline in cancer patient education and support services delivery. How PADRES's program model could be integrated into the research infrastructure and work across PADRES and UCLA was discussed in several meetings. As a result, PADRES and UCLA interviewed and selected four student interns to work with the research team. The interns were comprised of a public health graduate student, a medical student, and two undergraduates, one of whom was a cancer survivor. Two were assigned to work at PADRES, and the other two were at UCLA. A cross-training manual was developed by the PADRES and UCLA directors to establish training guidelines for interns to participate at both sites. The cross-training internship provided a mentorship component to teach research skills, learn to develop and evaluate culturally-relevant, age-appropriate health education materials, and understand how a nonprofit organization works.

PADRES-UCLA Research Team $(\boldsymbol{n}=8)$ : The research team included the directors $(n=2)$, the research coordinator $(n=1)$, the community liaison $(n=1)$, and cross-training interns $(n=4)$. The research team held in-service meetings every other month (alternating between sites) to review project goals, develop/ revise recruitment materials, and outline/review meeting agendas.

\section{Advisory Committees}

We used Jones's theoretical framework for CPPR to guide our approach to the identification of potential advisory committee members. This framework stresses the engagement of both diverse community and academic stakeholders in a two-way, equitable learning process from beginning to end in order to close science-community practice gaps (Feasibility Studies for Collaborative Interactions for Minority/Cancer Center Partnership, 2009; L. Jones, 2009; L. Jones, Meade, Forge, Moini, et al., 2009). We used a broad definition of "stakeholders" to include persons interested in or affected by the particular issue of childhood and AYA cancer survivorship in minority groups (Israel et al., 2008; L. Jones, 2009; L. Jones, Meade, Forge, Moini, et al., 2009; L. Jones, Meade, Norris, Lucas-Wright, et al., 2009; L. Jones, Wells, Meade, et al., 2009; L. Jones, Wells, Norris, et al., 2009). Using this definition, the core members of the PADRES-UCLA partnership established two separate committees the Internal Advisory Committee (IAC) and the Community Advisory Group (CAG) - which included key stakeholders:

Internal Advisory Committee (IAC) $(\boldsymbol{n}=11)$ : The PADRES-UCLA directors identified six community experts from PADRES and five academic experts from UCLA to form this committee. It was important that the IAC 
Table 1. Internal Advisory Committee (IAC) Members ( $\mathrm{n}=11$ )

\begin{tabular}{ll}
\hline \multicolumn{1}{c}{ PADRES } & \multicolumn{1}{c}{ UCLA } \\
\hline $\begin{array}{l}\text { PADRES's Family Case Manager and } \\
\text { Community Liaison }\end{array}$ & $\begin{array}{l}\text { Medical Cancer Survivorship Oncologist, Clinical and Health Services } \\
\text { Researcher }\end{array}$ \\
\hline $\begin{array}{l}\text { PADRES's Volunteer and Family Activities } \\
\text { Manager }\end{array}$ & $\begin{array}{l}\text { Primary Care Physician and Health Services Research Director for Internal } \\
\text { Medicine }\end{array}$ \\
\hline $\begin{array}{l}\text { Oncology Nurse and Member of PADRES's } \\
\text { Medical Advisory Committee }\end{array}$ & $\begin{array}{l}\text { Pediatric and Adolescent Psychiatrist (background in research pertaining to } \\
\text { childhood cancer survivors and their parents) }\end{array}$ \\
\hline Spanish Language Interpreter & $\begin{array}{l}\text { Social/Health Psychologist (background in socioeconomic and race/ethnicity- } \\
\text { based health disparities research) }\end{array}$ \\
\hline $\begin{array}{l}\text { CEO and Director of PADRES (known } \\
\text { community expert) }\end{array}$ & Pediatric Cancer Survivorship Oncologist and Health Services Researcher \\
\hline PADRES's Family Case Manager & \\
\hline
\end{tabular}

included equal representation of members from PADRES and UCLA with expertise in cancer survivorship care and in educating the Latino community in this subject. They met biannually to: 1 ) provide expertise on the deficit in culturally-relevant survivorship educational materials for Latino AYA cancer survivors and their families; 2) lend their scientific and community expertise to operationalize and evaluate the partnership's goals and objectives for proposed educational interventions; 3 ) provide recommendations on the development and testing of proposed educational interventions; and 4) offer their expert opinions on how to disseminate proposed educational interventions in the community. Table 1 provides descriptions of the key stakeholders that comprised the IAC.

Community Advisory Group (CAG) ( $n=24)$ : The PADRES and UCLA leadership team identified eight AYA survivors (ages 15-39 years old) who in turn invited family members they acknowledged as an important part of their cancer care experience. In total, twelve parents and four extended family members of the AYA cancer survivors joined to complete this committee. Table 2 provides descriptions of the key stakeholders that comprised the CAG. Their role was to represent the interests of the Latino AYA survivor community by providing ongoing feedback on the partnership's operations as well as proposed educational interventions. During quarterly meetings facilitated by the community liaison, members engaged in open discussions and provided feedback regarding the operation of the partnership and proposed education interventions. The community liaison then shared notes from these meetings with the core members of the PADRES-UCLA partnership and the IAC, which prompted changes - for example, one educational intervention's (a photonovela's) content was adjusted to include concrete illustrations depicting practical steps a survivor could take to minimize the risk of secondary cancers. When changes were made and implemented by the core members of the PADRES-UCLA partnership and the IAC based on the CAG feedback, a reiterative feedback loop occurred where the community liaison communicated back to the CAG at subsequent meetings on how their recommendations were implemented. In this way, the $\mathrm{CAG}$ was given shared power throughout the research process. Members signed a one-year 
Table 2. Demographic Information for Community Advisory Group (CAG) Members ( $n=24)$

\begin{tabular}{lc}
\hline Cancer Survivors $(n)$ & 8 \\
\hline Age at Diagnosis & 7 -14 years old \\
\hline Current Ages of Survivors & $18-26$ years old \\
\hline Cancer Diagnosis & $\begin{array}{c}\text { Leukemia, Hodgkin's Lymphoma, Central Nervous System } \\
\text { (CNS) Lymphoma, Germ Cell Tumor, Other }\end{array}$ \\
\hline Years Off Treatment & $6-15$ \\
\hline Parents (Mother or Father) $(n)$ & 12 \\
\hline Extended Family (Brother or Sister) $(n)$ & 4 \\
\hline Age Range of Family Members (Parents/Extended) & $18-54$ years old \\
\hline Member Ethnicity & All Mexican \\
\hline
\end{tabular}

commitment prior to serving on the committee. The CAG members received certificates of recognition and T-shirts (noting their membership) for their commitment to and participation in the project.

\section{Measures/Data Collection}

A process evaluation was used to assess equality between the community and academic sections of the partnership and implementation of the five core principles of CPPR. The process evaluation included qualitative interviews of the cross-training interns and review of meeting agendas and minutes (Table 3 ). Detailed notes of recommended agenda revisions from community members were facilitated through tracking changes in the agenda documents. These notes and revisions were reviewed and discussed by the research assistant and the community liaison at each of the PADRES-UCLA research team and IAC meetings to ensure full collaboration. For each of the different stakeholder meetings, the research assistant or a cross-training intern was assigned to take detailed meeting minutes of discussions from which major themes could be identified and analyzed. The final meeting agendas and minutes were analyzed for key themes by the research team and then presented to the two directors, after which revisions were made to the infrastructure and/or any educational interventions in development to ensure the voice of the community was integrated and to add to trust of the partnership.

\section{Data Analysis}

A grounded theory approach by Glaser and Strauss, which uses inductive reasoning, was utilized to identify key components of the infrastructure that helped establish the research partnership between PADRES and UCLA from the community's perspective (Bryant \& Charmaz, 2007). The qualitative data obtained and analyzed consisted of interviews of the cross-training interns at the completion of their internships (they were interviewed by either the directors, research coordinator, or community liaison), meeting agendas, and meeting notes. Meeting minutes documented discussions had by the CAG and IAC that included, for example: 1) deficits in culturally-relevant survivorship educational materials for Latino AYA cancer survivors and their families; 2) the operation and evaluation of the PADRES-UCLA partnership as well as 


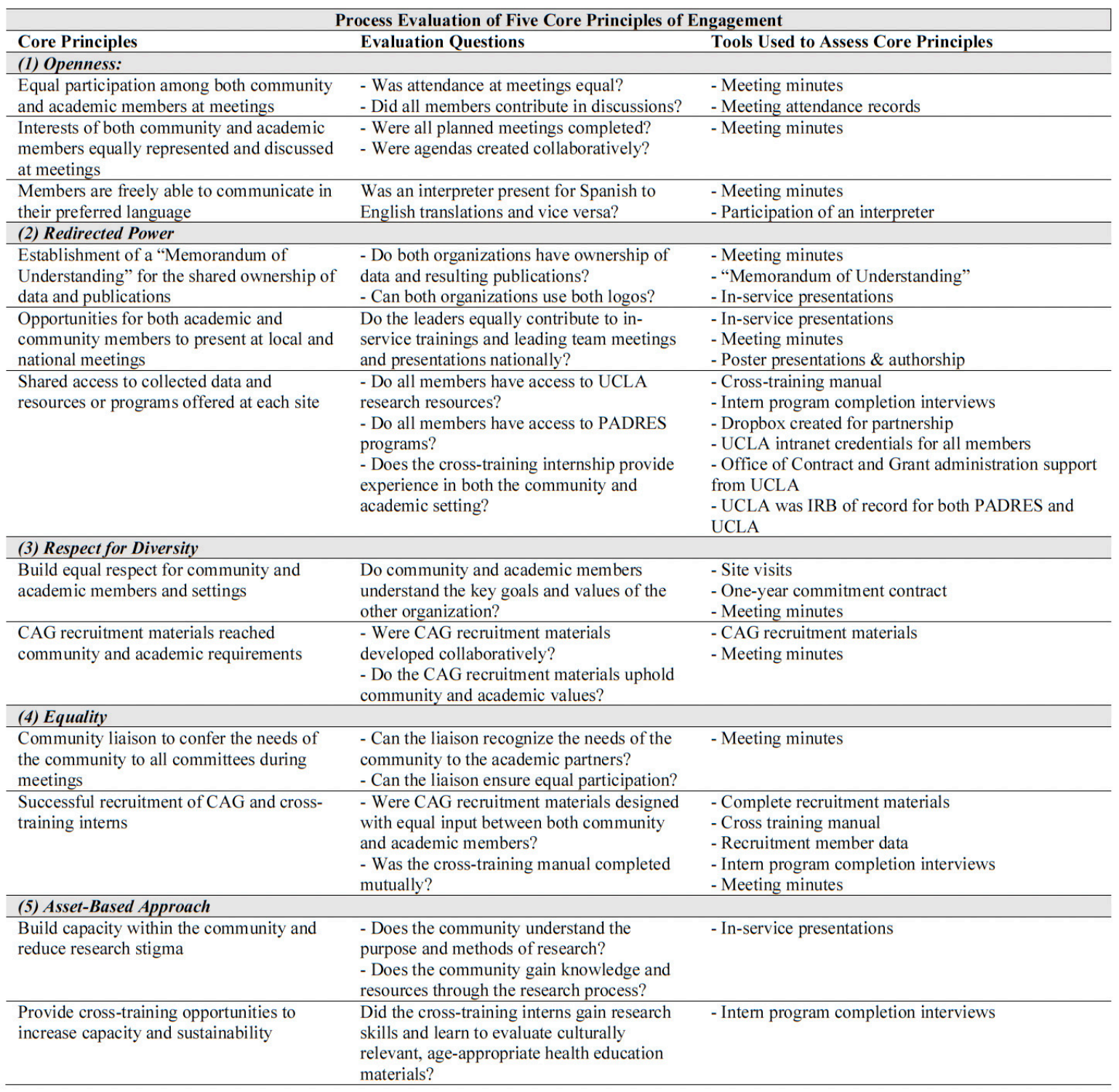

Table 3. A Process Evaluation Guide to Establish a Community-Partnered Organization Based on CPPR Methodology

its stated goals and objectives; 3 ) views concerning the risks and benefits of the PADRES-UCLA partnership; and 4) how to integrate community voices into the infrastructure itself. Key themes were drawn from finalized agendas and minutes from the CAG and IAC meetings, reviewed, and then coded. Transcripts of the cross-training intern interviews were reviewed using open coding. Codes from all data sources were categorized and refined through a constant comparative method, from which major themes were identified (Kolb, 2012). Exemplary texts were taken from transcripts of intern interviews. 
Results

Assessment of Adherence to the Five Core Principles of CPPR

\section{Openness}

\section{Theme 1: Regularly Scheduled Meetings at Both Sites Were Important for Team Building}

The PADRES and UCLA directors met monthly, the PADRES-UCLA research team met every other month, the IAC met biannually, and the CAG met quarterly. In these meetings, open communication was reinforced through members, who provided constructive feedback for partnership formation, discussed needs assessment of the community, and completed deliverables. Additionally, agendas were distributed one to three days prior to meetings to give all partners adequate time to submit additions and revisions beforehand. This practice was highly valued by community partners as they felt it ensured their voice was represented during meetings and provided opportunity to discuss agenda items important to the community perspective.

\section{Theme 2: Opportunities to Communicate in Preferred Language Other than English is Critical}

Meetings were primarily conducted in English. However, some community members felt more comfortable providing their discussion points in Spanish. A Spanish interpreter familiar to PADRES-affiliated members attended all meetings. When prompted, the interpreter would provide translations for members in order to ensure their opinions were expressed and understood properly. This increased the engagement and comfort of all partners and did not significantly impact meeting structure or duration.

\section{Redirected Power (Shared Leadership, Resources, and Data Ownership)}

\section{Theme 1: Presentation by Both Directors at National Meetings Strengthened the Research Partnership}

The P20 grant offered the opportunity for both directors to present their partnership's work at a national meeting. The conference gave the PADRES director and community members the opportunity to present work, providing academic recognition as a research partner. Both directors found this experience valuable to strengthen their partnership and for ongoing networking opportunities.

\section{Theme 2: The Partnership Integrated Previously Established Programs and Resources to Engage Community and Academic Members}

All members from the PADRES-UCLA research team, IAC, and CAG participated in PADRES's educational programs for patients and family members and attended the UCLA cancer center's lecture series on cancer prevention and research. This provided bi-directional, bi-institutional redirected power and facilitated the sharing of resources across the partnership. UCLA provided administrative and technical support by supplying Dropbox, IRB support, and access to UCLA's Office of Contracts and Grants. PADRES 
provided educational and community resource materials previously developed for the survivor community. This included the use of PADRES’s trademarked cartoon characters of a childhood cancer patient (Esperanza) and her family (Padres Contra El Cáncer, 2012). For example, when developing recruitment materials, the PADRES-UCLA research team developed initial drafts and presented them to the CAG for their recommended revisions to encourage feedback from multiple perspectives outside of the research team. Materials produced integrated PADRES's prior experience with marketing to the Latino community and their trademark cartoons of Esperanza and her family.

\section{Theme 3: The PADRES and UCLA Partnership Provided Cross- Training Interns Valuable Learning Experience in Community Health Research}

Program completion interviews indicated that interns valued their involvement with the partnership. Quotes from interns included:

"Through my cross-training, I learned the values of persistency and preparation...for community organizations."

"Once I began helping with research at UCLA, I learned how important the preliminary work is for understanding how Latino families are affected by childhood cancer, before implementation of a research intervention.”

\section{Theme 4: Development of a "Memorandum of Understanding" Was Important to Present Work Uniformly}

Formal guidelines for the use of UCLA and PADRES trademarks, logos, and images in presentations and resulting publications were developed. This served as another formal process to define the equal partnership.

\section{Respect for Diversity}

\section{Theme 1: Participation in Community-Based Activities by Academic Members Were Critical to Foster Mutual Respect}

Members from UCLA volunteered at PADRES events to build an understanding of community priorities and needs. At these events, the community liaison led discussions with community participants on key issues affecting the survivor population. The community liaison asked open ended questions to community participants focusing on survivorship education and strategies to develop new educational materials for the Latino AYA survivor community. This was followed by time for the academic members in attendance to ask further questions to the community participants. Also, research team members engaged with CAG members following their quarterly meetings regarding their thoughts and critiques regarding the partnership's operations and proposed educational interventions; therefore, both academic and community partners received ongoing feedback from each other. 


\section{Theme 2: Having Work Products Completed by Both Community and Academic Team Members Was Effective in Building Mutual Respect}

The PADRES-UCLA directors created the cross-training program manual together. It included standard procedures designed to assist interns in carrying out their duties at both partner sites. Using PADRES's expertise in marketing to the Latino community while following UCLA IRB protocol, the PADRESUCLA research team created culturally-targeted CAG recruitment material for families and patients at the appropriate literacy level.

\section{Equality}

\section{Theme 1: The Community Liaison Was Critical to Facilitate Equal Participation by Both Community and Academic Members}

During the first IAC meeting, the community liaison noted that academic members dominated discussions. She later gave feedback to academic members that some community members experienced a negative feeling they attributed to a power differential in favor of the academic members. During subsequent meetings, time was allocated to explore community members' discussion points, and the community liaison encouraged active listening from academic partners.

\section{Asset-Based Approach}

\section{Theme 1: Leveraging Academic and Community Expertise to Ensure Values, Beliefs, and Health-Related Concerns of the Latino AYA Community Were Addressed}

The shared contributions of the IAC and CAG members were valuable in the development process of the proposed interventions. Both working groups underwent thorough evaluation and consensus-decision-making processes to identify appropriate strategies and educational themes to include in the interventions.

\section{Theme 2: In-Service Meetings Provided Opportunities for Capacity Building and Sustainability}

Core members of the PADRES-UCLA partnership conducted quarterly educational seminars on health disparities topics and research methodology as well as journal clubs that were open to other members of the research team (including the cross-training interns) as well as IAC and CAG members. Topics included "Recruiting Hard-to-Reach Populations," "Institutional Review Board - What is it?," and "Value of Research Performed by Community Organizations." After presentations, members would discuss the topic's relevance to their own interests within cancer survivorship. In addition to IAC/CAG meetings and PADRES community events, these educational seminars provided an opportunity for professional career development through education and research training. 


\section{Discussion}

To our knowledge, this is the first description of a CPPR research model between an NCI-designated cancer center and a community-based institution aimed at developing culturally-tailored educational interventions for the Latino AYA cancer survivor population. Community-based organizations have a long-standing history of providing patients and their families with services they would otherwise be unable to attain due to barriers accessing the traditional medical setting (Hoffman \& Stovall, 2006; Shelby et al., 2002). Research models such as CPPR could provide new, targeted research interventions aimed at improving access to risk-based survivorship care. As shown in Table 3, we used the five core principles of CPPR to establish an effective method for building our sustainable partnership that developed survivorship interventions and acknowledged organizational, community and personal levels of this research partnerships (Macaulay et al., 1999).

Several important findings emerged through the infrastructure development of this CPPR partnership. Attention to the core principle of openness was critical to engage members of the Latino community to discuss their cancer survivorship needs. Previous studies have described the challenges faced when discussing sensitive issues with community members (Burke et al., 2013; Thomsen et al., 2007) and have suggested that speaking about the cancer experience can be very stigmatizing, particularly in the Latino community (Casillas et al., 2010). Explicitly working to foster open communication during meetings and events encouraged community members to openly and safely discuss their experiences with cancer. In this study, open communication was uniquely facilitated through the inclusion of a community liaison as a key member of the research team. The liaison led CAG meetings, was available to address any immediate $\mathrm{CAG}$ concerns, and provided feedback to the CAG, IAC, and research team through an iterative feedback loop. This facilitated the understanding of community needs and assets, revisions to the infrastructure and its educational work products, and the integration of many different voices into the infrastructure itself.

The principle of redirected power through shared leadership and resources was critical to developing culturally-tailored research information materials. Previous studies have documented the challenges of producing appropriate research description and recruitment materials for AYA childhood cancer survivors as well as those from minority racial/ethnic groups (Seltzer et al., 2014). Using input provided by community members, we designed CAG recruitment material tailored for Latino AYA survivors and their families at appropriate literacy levels. This process involved eliciting community feedback regarding wording and readability regarding to cancer terminology that was then incorporated by the research team. An iterative feedback loop would continue in this fashion until a mutually agreed upon final work product was accepted by both community and academic partners. 
Additionally, we integrated PADRES's previously established educational programs into our CPPR model. This decreased recipients' stigma associated with research participation, as PADRES was a known, trusted organization with more than 20 years of experience in serving the Latino cancer survivorship community. This trust in PADRES allowed the community to open up and discuss difficulties in their cancer experience, including some that might be traditionally avoided due to concerns of stigma (Kim et al., 2005).

Through recognition of the CPPR principle of respect for diversity, we were able to recruit a diverse population of cancer survivors. Previous studies where community partners develop and manage recruitment efforts have more success in recruiting minority populations (Horowitz et al., 2009), which was true in this project as well. PADRES had already developed a strong rapport and trust among the Latino AYA survivor community. With their efforts, the partnership recruited a large and committed group of CAG members to partner in the creation and evaluation of different educational interventions, one of which was a photonovela, and members stayed actively engaged in the year-long project, without attrition (Casillas et al., 2020).

A community liaison was critical to fostering a cohesive partnership. She served as a voice for the Latino community by acting as a full research team participant and resolving conflicts between community and academic members through fostering collaboration. This, along with the guidance from the academic and community experts, ensured that the concerns of the Latino community were equally represented within the partnership and that intervention materials represented the interests of both the Latino and academic communities on survivorship education.

Implementing in-service trainings on research topics to promote skill building during the partnership helped contribute to the sustainability of the program. Previous studies have found that community members desire skill building in research methodology and providing these opportunities stimulated member engagement (Baiardi et al., 2010).

Similar to other studies involving CPPR methodology, the creation of our partnership's infrastructure faced several barriers and challenges. As in other CPPR programs, establishing and adhering to timelines and deadlines for meetings and the creation, evaluation, and testing of the partnership's work products was difficult (Metzler et al., 2003). For example, during the infrastructure's early development, both PADRES and UCLA members had difficulties establishing adequate time to devote to the partnership: PADRES held community events, while UCLA had research-related deadlines for various projects - both of which were time-intensive. To address these challenges, the research assistant, community liaison, and interns integrated calendar discussions into their weekly meeting agendas. Discussions were reviewed weekly and would include noting action items with specific due dates. Also, due to mutual trust between the PADRES and UCLA directors, the programs' other project timelines/deadlines and how they could potentially support each other were frequent topics of discussion. There was also difficulty 
in finding sufficient and continuous funding to support this project. However, the PADRES-UCLA research team leveraged available philanthropic and volunteer resources to reach the optimal capacity of this initiative.

In conclusion, our project's infrastructure development was a critical first step required to develop, evaluate, and test culturally-tailored survivorship educational interventions to improve survivorship care knowledge and intent to seek risk-based survivorship care in a diverse population of childhood AYA cancer survivor community. The five CPPR core principles used in this study describe one potential approach to establishing a community organization and cancer center partnership for future research in diverse communities of cancer survivors.

\section{Conflicts of Interest}

The authors have no conflicts of interest to disclose.

\section{Acknowledgements}

This research was supported by the National Institute of Health (grant PAR-09-201 entitled "Feasibility Studies for Collaborative Interaction for Minority Institution/Cancer Center Partnership (P20)”. The authors sincerely thank the Latino AYA survivor community and their families from the greater Los Angeles area, including the Community Advisory Group members, team members Padres El Contra Cáncer, and research assistants who contributed throughout the project from the UCLA Jonsson Comprehensive Cancer Center, including the cross-training interns for making this research partnership possible. 


\section{References}

Baiardi, J., Brush, B., \& Lapides, S. (2010). Common issues, different approaches: Strategies for community-academic partnership development. Nursing Inquiry, 17, 289-296. https://doi.org/ 10.1111/j.1440-1800.2010.00509.x

Berg, C., Stratton, E., Esiashvili, N., Mertens, A., \& Vanderpool, R. C. (2016). Providers' Perspectives of Survivorship Care for Young Adult Survivors of Childhood Cancer. Journal of Cancer Education, 31(1), 31-38. https://doi.org/10.1007/s13187-015-0848-6

Bhakta, N., Liu, Q., Yeo, F., Baassiri, M., Ehrhardt, M. J., Srivastava, D. K., Metzger, M. L., Krasin, M. J., Ness, K. K., Hudson, M. M., Yasui, Y., \& Robison, L. L. (2016). Cumulative burden of cardiovascular morbidity in paediatric, adolescent, and young adult survivors of Hodgkin's lymphoma: an analysis from the St Jude Lifetime Cohort Study. The Lancet Oncology, 17(9), 1325-1334. https://doi.org/10.1016/s1470-2045(16)30215-7

Bryant, A., \& Charmaz, K. (2007). The Sage handbook of grounded theory. Sage.

Burke, J. G., Hess, S., Hoffmann, K., Guizzetti, L., Loy, E., Gielen, A., Bailey, M., Walnoha, A., Barbee, G., \& Yonas, M. (2013). Translating community-based participatory research principles into practice. Progress in Community Health Partnerships: Research, Education, and Action, 7(2), 115-122. https://doi.org/10.1353/cpr.2013.0025

Casillas, J. N., Kahn, K. L., Doose, M., Landier, W., Bhatia, S., Hernandez, J., \& Zeltzer, L. K. (2010). Transitioning childhood cancer survivors to adult-centered healthcare: insights from parents, adolescent, and young adult survivors. Psychooncology, 19(9), 982-990. https://doi.org/10.1002/ pon. 1650

Casillas, J. N., Schwartz, L. F., Gildner, J. L., Crespi, C. M., Ganz, P. A., Kahn, K. L., Stuber, M. L., Bastani, R., Morales, S., Quintana, K., Gonzalez, A., Casas, E., \& Barboa, E. (2020). Engaging Latino Adolescent and Young Adult (AYA) Cancer Survivors in Their Care: Piloting a Photonovela Intervention. Journal of Cancer Education. https://doi.org/10.1007/s13187-020-01724-2

Casillas, J. N., Syrjala, K. L., Ganz, P. A., Hammond, E., Marcus, A. C., Moss, K. M., Crespi, C. M., Lu, P., McCabe, M. S., Ford, J. S., Jacobs, L. A., Pucci, D., Palmer, S. C., Termuhlen, A. M., Diller, L., Campbell, M., Jones, B., \& Friedman, D. L. (2011). How confident are young adult cancer survivors in managing their survivorship care? A report from the LIVESTRONG ${ }^{\text {TM }}$ Survivorship Center of Excellence Network.J Cancer Surviv, 5(4), 371-381. https://doi.org/10.1007/ $\underline{\text { s11764-011-0199-1 }}$

Colon-Otero, G., Smallridge, R. C., Solberg, L. A., Jr., Keith, T. D., Woodward, T. A., Willis, F. B., \& Dunn, A. N. (2008). Disparities in participation in cancer clinical trials in the United States: a symptom of a healthcare system in crisis. Cancer, 112(3), 447-454. https://doi.org/10.1002/ cncr.23201

Feasibility Studies for Collaborative Interactions for Minority/Cancer Center Partnership. (2009). National Cancer Institute, Department of Health and Human Services. https://grants.nih.gov/ grants/guide/pa-files/PAR-07-230.html

Gleeson, H. K., \& Shalet, S. M. (2001). Endocrine complications of neoplastic diseases in children and adolescents. Current Opinion in Pediatrics, 13(4), 346-351. https://doi.org/10.1097/ 00008480-200108000-00011

Hallquist Viale, P. (2016). Late Effects: Focus on Adolescent and Young Adult Cancer Survivors. Journal of the Advanced Practitioner in Oncology, 7(1), 15-16. https://doi.org/10.6004/ jadpro.2016.7.1.1 
Hoffman, B., \& Stovall, E. (2006). Survivorship Perspectives and Advocacy.Journal of Clinical Oncology: Official Journal of the American Society of Clinical Oncology, 24, 5154-5159. https://doi.org/10.1200/JCO.2006.06.5300

Horowitz, C. R., Brenner, B. L., Lachapelle, S., Amara, D. A., \& Arniella, G. (2009). Effective recruitment of minority populations through community-led strategies. American Journal of Preventive Medicine, 37(6 Suppl 1), S195-200. https://doi.org/10.1016/j.amepre.2009.08.006

Howlader, N., Noone, A. M., Krapcho, M., Miller, D., Brest, A., Yu, M., Ruh, J., Tatalovich, Z., Mariotto, A. B., Lewis, D. R., Chen, H. S., Feuer, E. J., \& Cronin, K. A. (2019). SEER Cancer Statistics Review, based on November 2018 SEER data submission, posted to the SEER web site, April 2019. National Cancer Institute. https://seer.cancer.gov/csr/1975_2016/

Hudson, M. M., Mertens, A. C., Yasui, Y., Hobbie, W., Chen, H., Gurney, J. G., Yeazel, M., Recklitis, C. J., Marina, N., Robison, L. R., \& Oeffinger, K. C. (2003). Health status of adult long-term survivors of childhood cancer: a report from the Childhood Cancer Survivor Study. JAMA, 290(12), 1583-1592. https://doi.org/10.1001/jama.290.12.1583

Hudson, M. M., \& Patte, C. (2008). Education and health promotion in adolescent and young adult cancer survivors. Pediatric Blood $\Xi^{\circ}$ Cancer, 50(5 Suppl), 1105-1108. https://doi.org/10.1002/ pbc. 21458

Im, E. O., Chee, W., Lim, H. J., \& Liu, W. M. (2008). An online forum exploring needs for help of patients with cancer: gender and ethnic differences. Oncology Nursing Forum, 35(4), 653-660. https://doi.org/10.1188/08.Onf.653-660

Institute of Medicine. (2001). Crossing the Quality Chasm: A New Health System for the 21st Century. National Academies Press (US). https://doi.org/10.17226/10027

Israel, B. A., Parker, E. A., \& Becker, A. B. (2008). Critical Issues in Developing and Following Community-Based Participatory Research Principles. Jossey-Bass.

Jones, B. L., Volker, D. L., Vinajeras, Y., Butros, L., Fitchpatrick, C., \& Rossetto, K. (2010). The meaning of surviving cancer for Latino adolescents and emerging young adults. Cancer Nursing, 33(1), 74-81. https://doi.org/10.1097/NCC.0b013e3181b4ab8f

Jones, L. (2009). Preface: Community-partnered participatory research: how we can work together to improve community health. Ethnicity E̊ Disease, 19 (4 Suppl 6), S1-S2.

Jones, L., Meade, B., Forge, N., Moini, M., Jones, F., Terry, C., \& Norris, K. (2009). Begin your partnership: the process of engagement. Ethnicity छ? Disease, 19 (4 Suppl 6), S8-S16.

Jones, L., Meade, B., Norris, K., Lucas-Wright, A., Jones, F., Moini, M., Jones, A., \& Koegel, P. (2009). Develop a vision. Ethnicity E̊ Disease, 19 (4 Suppl 6), S17-S30.

Jones, L., Wells, K., Meade, B., Forge, N., Lucas-Wright, A., Jones, F., Young-Brinn, A., Jones, A., \& Norris, K. (2009). Work through the valley: do. Ethnicity E' Disease, 19, S6-39.

Jones, L., Wells, K., Norris, K., Meade, B., \& Koegel, P. (2009). The vision, valley, and victory of community engagement. Ethnicity $\sigma^{\circ}$ Disease, 19 (4 Suppl 6), S3-S7.

Kaur, J. S., Coe, K., Rowland, J., Braun, K. L., Conde, F. A., Burhansstipanov, L., Heiney, S., KagawaSinger, M., Lu, Q., \& Witte, C. (2012). Enhancing life after cancer in diverse communities. Cancer, 118(21), 5366-5373. https://doi.org/10.1002/cncr.27491

Kim, S., Flaskerud, J. H., Koniak-Griffin, D., \& Dixon, E. L. (2005). Using community-partnered participatory research to address health disparities in a Latino community. Journal of Professional Nursing, 21(4), 199-209. https://doi.org/10.1016/j.profnurs.2005.05.005

Kolb, S. M. (2012). Grounded theory and the constant comparative method: Valid research strategies for educators. Journal of Emerging Trends in Educational Research and Policy Studies, 3(1), 83-86. 
Lewis, D. R., Seibel, N. L., Smith, A. W., \& Stedman, M. R. (2014). Adolescent and young adult cancer survival. Journal of the National Cancer Institute Monographs, 2014(49), 228-235. https://doi.org/10.1093/jncimonographs/lgu019

Macaulay, A. C., Commanda, L. E., Freeman, W. L., Gibson, N., McCabe, M. L., Robbins, C. M., \& Twohig, P. L. (1999). Participatory research maximises community and lay involvement. North American Primary Care Research Group. British Medical Journal, 319(7212), 774-778. https://doi.org/10.1136/bmj.319.7212.774

Medlow, S., Patterson, P., \& Baird, B. (2015). Exploring Survivorship Care for Adolescent and Young Adult Cancer Survivors in Australia. CanTeen Australia. https://www.canteen.org.au/wp-content/ uploads/2016/09/Adolescent-and-Young-Adult-Cancer-Survivorship-Report.pdf

Mertens, A. C., Yasui, Y., Neglia, J. P., Potter, J. D., Nesbit, M. E., Jr., Ruccione, K., Smithson, W. A., \& Robison, L. L. (2001). Late mortality experience in five-year survivors of childhood and adolescent cancer: the Childhood Cancer Survivor Study.Journal of Clinical Oncology, 19(13), 3163-3172. https://doi.org/10.1200/jco.2001.19.13.3163

Metzler, M. M., Higgins, D. L., Beeker, C. G., Freudenberg, N., Lantz, P. M., Senturia, K. D., Eisinger, A. A., Viruell-Fuentes, E. A., Gheisar, B., Palermo, A. G., \& Softley, D. (2003). Addressing urban health in Detroit, New York City, and Seattle through community-based participatory research partnerships. American Journal of Public Health, 93(5), 803-811. https://doi.org/ 10.2105/ajph.93.5.803

Miller, K. D., Siegel, R. L., Lin, C. C., Mariotto, A. B., Kramer, J. L., Rowland, J. H., Stein, K. D., Alteri, R., \& Jemal, A. (2016). Cancer treatment and survivorship statistics, 2016. CA: A Cancer Journal for Clinicians, 66(4), 271-289. https://doi.org/10.3322/caac.21349

Munoz, A. R., Kaiser, K., Yanez, B., Victorson, D., Garcia, S. F., Snyder, M. A., \& Salsman, J. M. (2016). Cancer experiences and health-related quality of life among racial and ethnic minority survivors of young adult cancer: a mixed methods study. Support Care Cancer, 24(12), 4861-4870. https://doi.org/10.1007/s00520-016-3340-x

National Cancer Institute. (2017). UCLA Jonsson Comprehensive Cancer Center. https://www.cancer.gov/research/nci-role/cancer-centers/find/uclajonsson

National Cancer Institute. (2019). NCI-Designated Cancer Centers. https://www.cancer.gov/ research/nci-role/cancer-centers

Nguyen, A. B., Chawla, N., Noone, A.-M., \& Srinivasan, S. (2014). Disaggregated Data and Beyond: Future Queries in Cancer Control Research. Cancer Epidemiology Biomarkers E Prevention, 23(11), 2266-2272. https://doi.org/10.1158/1055-9965.Epi-14-0387

Padres Contra El Cáncer. (2012). Padres Contra El Cáncer. https://www.iamhope.org

Seltzer, E. D., Stolley, M. R., Mensah, E. K., \& Sharp, L. K. (2014). Social networking site usage among childhood cancer survivors - a potential tool for research recruitment? Journal of Cancer Survivorship, 8(3), 349-354. https://doi.org/10.1007/s11764-014-0348-4

Shelby, R. A., Taylor, K. L., Kerner, J. F., Coleman, E., \& Blum, D. (2002). The role of communitybased and philanthropic organizations in meeting cancer patient and caregiver needs. CA: A Cancer Jouranl for Clinicians, 52(4), 229-246. https://doi.org/10.3322/canjclin.52.4.229

Stolley, M. R., Sharp, L. K., Tangney, C. C., Schiffer, L. A., Arroyo, C., Kim, Y., Campbell, R. T., Schmidt, M. L., Breen, K., Kinahan, K. E., Dilley, K. J., Henderson, T. O., Korenblit, A. D., \& Seligman, K. (2015). Health behaviors of minority childhood cancer survivors. Cancer, 121(10), 1671-1680. https://doi.org/10.1002/cncr.29202

Surbone, A., \& Halpern, M. T. (2016). Unequal cancer survivorship care: addressing cultural and sociodemographic disparities in the clinic. Support Care Cancer, 24(12), 4831-4833.

https://doi.org/10.1007/s00520-016-3435-4 
Thomsen, D. K., Pedersen, A. F., Johansen, M. B., Jensen, A. B., \& Zachariae, R. (2007). Breast cancer patients' narratives about positive and negative communication experiences. Acta Oncologica, 46(7), 900-908. https://doi.org/10.1080/02841860701261550 